\title{
Free software: a review, in the context of disaster management
}

Mathias Leidig

Richard Teeuw*

University of Portsmouth, School of Earth \& Environmental Sciences, Portsmouth, UK

\begin{abstract}
This article examines the nature of freely available geospatial software and information systems in the context of disaster management. The use of geospatial data is crucial to effective disaster management, from preparedness to response and recovery. However, to make efficient use of available data and information - before, during and after a disaster - reliable software is required. The software applications examined in this paper range from Geographical Information Systems, to the processing of remotely sensed images, crowd-source mapping, web applications and content management systems. Trends and challenges are considered, and guidelines are given, to foster and encourage the provision of information by Freeware and Open Source Software. Free geoinformatics can help to optimize the limited financial, technological and manpower resources that many organisations face, providing a sustainable input to analytical activities.
\end{abstract}

Keywords: FOSS; Remote sensing; GIS; Geoinformatics; Disaster preparedness; Disaster management

\section{Introduction}

In this article we discuss freeware and open source software, then examine various freeware projects and assign functional categories for a comparative analysis. Guidelines are given on the selection of free software, including criteria that should be considered prior to its use for disaster management applications. With regard to disaster management applications, the most important software belongs to the Geographic Information Systems (GIS) group, with a smaller set of software dealing with the processing of remotely sensed data. Emergency planners, crisis responders or disaster managers can use geoinformatics to maximum effect at the district or city administrative levels, incorporating community knowledge and involving local decision makers (Das, 2012).

\section{2 'Free Software' - what is it?}

The term 'Free and Open Source Software' (FOSS) was introduced in response to restrictions on access to source code for hardware drivers and software, which prohibited unauthorised changes to copyrighted computer code (Stallman, 1999, Grassmuck, 2004). Thus the idea of 'free software' has its origin in free 
speech, rather than free-of-cost. Steiniger and Hunter (2013) state that: "... a distinction between 'free software' and 'commercial software' is neither correct nor expresses the thinking of the creators of free software [..] that grants freedoms of use, modification and redistribution to the public; whereas commercial or proprietary software [..] takes these freedoms away..." According to the Free Software Foundation (2014), 'free software' grants four freedoms, to: (i) run the software for any purpose, (ii) study and adapt the software for own needs, (iii) redistribute the software, (iv) improve the software and release improvements to the public. Types of software licenses are reviewed by Steiniger and Bocher (2009). Open Source software, under the GNU General Public License (GNU, 2014) is desirable, but it may limit the software that can be used. To gain the interest of potential users in low-income countries (LICS), it is important that software is free and easily accessible. With regard to FOSS applications for sustainable development, UNESCO (2014) recognizes that:

- "Software plays a crucial role in access to information and knowledge;

- Different software models, including proprietary, open-source and free software, have many possibilities to increase competition, access by users, diversity of choice and to enable all users to develop solutions which best meet their requirements;

- The development of open, inter-operable, non-discriminatory standards for information handling and access are important elements in the development of effective infrastructure;

- The FOSS model provides tools and processes with which people can create, exchange, share and exploit software and knowledge efficiently;

- FOSS can play an important role in development... its free and open format make it a natural component of development efforts in the context of the Millennium Development Goals;

- Consistent support plays an important role in the success and sustainability of FOSS.

To encompass the ideas of UNESCO we define FOSS as 'Freeware and Open Source Software'. We use 'FOSS4geoinfo' as an abbreviation for: 'Freeware and Open Source Software for geoinformatics'. FOSS4geoinfo includes the free-of-charge aspect, as well as software for GIS, GPS data and remotely sensed data.

\section{Categories of geoinformatic software}

GIS software is used to create, manage, store, analyse and visualize geographic data. Steiniger and Hunter (2013) summarised seven types of GIS software: (i) Desktop GIS; (ii) Spatial Data Base Management Systems; (iii) Web Map Servers; (iv) Server GIS; (v) Web GIS clients; (vi) Mobile GIS and (vii) Libraries and Extensions, Plug-ins and application programming interfaces (APIs). We extend that software classification to include: Data Viewers; Web Applications; Cloud storage/sharing; and specialized Tools (e.g., radar data). 
A summary can be seen in Figure. 1, which shows geoinformatic software that have disaster management uses.

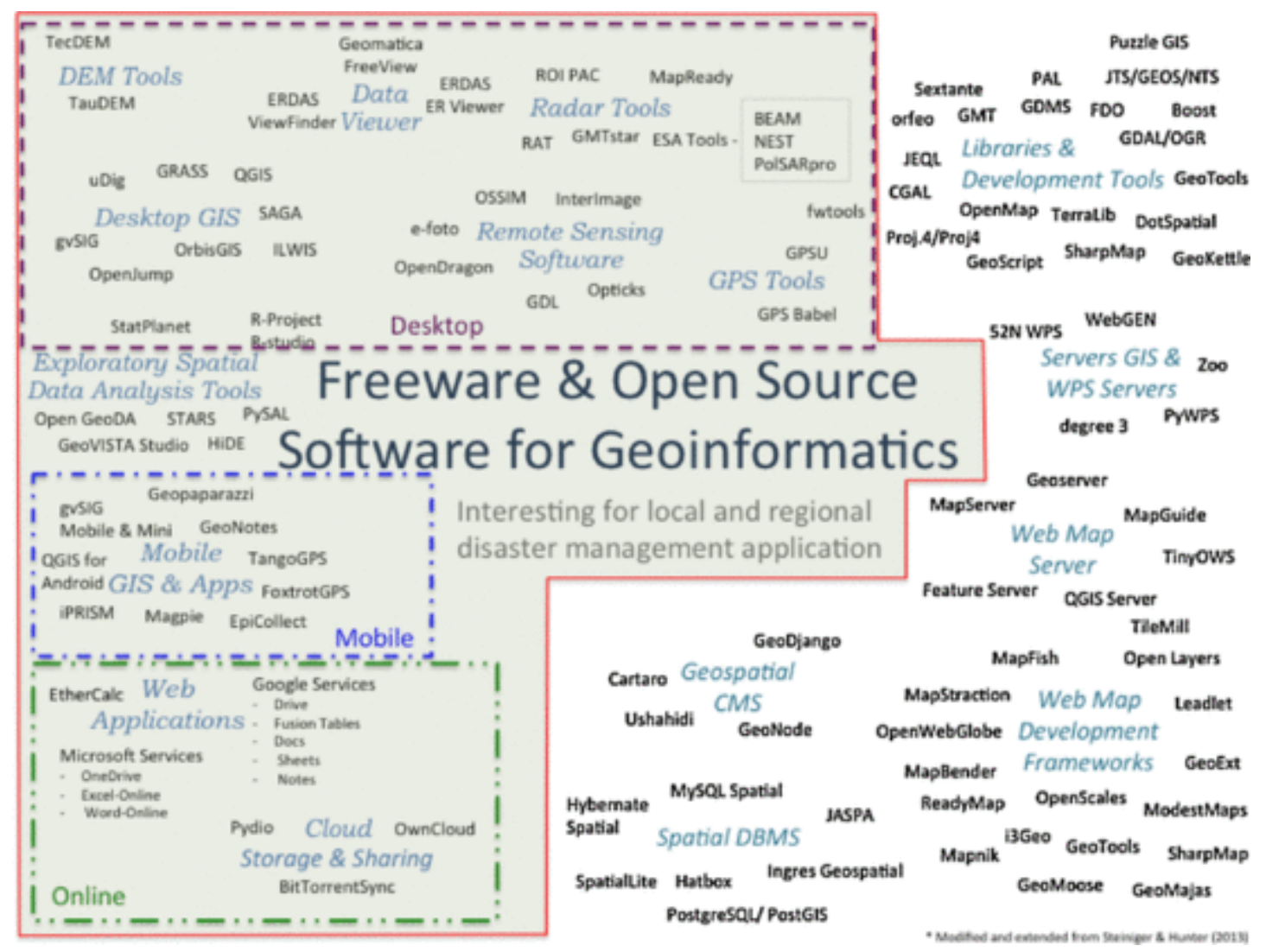

Fig. 1 Freeware and Open Source Geoinformatic Software Map for 2014. The inset box highlights Desktop software of particular use for disaster management.

The remote sensing domain is dominated by proprietary software. However, some free alternatives exist as standalone products, or as modules in FOSS4geoinfo sets. GIS software functionality encapsulates the functionality required to create maps and visualize geographical data. Remote Sensing software focuses on extracting information from geospatial imagery and image classification. GIS and Remote Sensing software capabilities should be used in conjunction to obtain the best results, from data pre-processing, to analysis and map creation or visualization. Remote Sensing software should be considered as a software type that complements GIS software, not as “a special form of desktop GIS” (Steiniger and Hunter, 2009).

The software most relevant for disaster management mapping and geoinformatic analysis can be grouped into: Desktop software, Mobile software and Online software (Figure. 1). These groups could be extended by online-applications and websites, however reliable Internet connectivity is not the norm in all countries. Table 1 shows how the software categories link with the stages of disaster management. 
Table 1 Relationship of the main FOSS4geoinfo systems (Fig. 1) with the main phases of disaster management.

\begin{tabular}{|c|c|c|c|}
\hline $\begin{array}{l}\text { Management } \\
\text { phase }\end{array}$ & $\begin{array}{l}\text { Geoinformatic } \\
\text { activity }\end{array}$ & $\begin{array}{l}\text { Corresponding FOSS4 geoinfo desktop } \\
\text { software }\end{array}$ & $\begin{array}{l}\text { Potential products of } \\
\text { geoinformatic activity }\end{array}$ \\
\hline $\begin{array}{l}\text { Disaster } \\
\text { prevention }\end{array}$ & Data Ccollection & $\begin{array}{l}\text { - Desktop GIS } \\
\text { - Moble GIS \& Apps } \\
\text { - GPS Tools } \\
\text { - Web Applications and Cloud Storage } \\
\text { - Geospatial CMS }\end{array}$ & $\begin{array}{l}\text { - plan critical } \\
\text { infrastructure e.g. } \\
\text { hospitals outside of } \\
\text { floodplains } \\
\text { - maps identifying } \\
\text { vulnerable sites, such } \\
\text { as schools or } \\
\text { retirement homes, that } \\
\text { may need special } \\
\text { assistance in } \\
\text { emergencies } \\
\text { - understanding the } \\
\text { terrain and } \\
\text { environment, e.g. to } \\
\text { avoid construction in } \\
\text { hazardous areas }\end{array}$ \\
\hline $\begin{array}{l}\text { Disaster } \\
\text { preparedness }\end{array}$ & $\begin{array}{l}\text { Data collection } \\
\text { \& managment, } \\
\text { some data analysis }\end{array}$ & $\begin{array}{l}\text { - GPS tools } \\
\text { - Desktop GIS } \\
\text { - Remote sensing Software, including } \\
\text { DEM \& radar tools } \\
\text { - Mobile GIS \& Apps } \\
\text { - Data Viewer }\end{array}$ & $\begin{array}{l}\text { - maps identifying } \\
\text { elements at risk, such } \\
\text { as vulnerable } \\
\text { infrastructure } \\
\text { - identification of } \\
\text { evacuation routes } \\
\text { - monitor land cover } \\
\text { and land use } \\
\text { - planning for refuge } \\
\text { areas and shelters }\end{array}$ \\
\hline $\begin{array}{l}\text { Disaster } \\
\text { response }\end{array}$ & $\begin{array}{l}\text { Data managment } \\
\& \text { data analysis }\end{array}$ & $\begin{array}{l}\text { - Desktop GIS } \\
\text { - with processing and analysis } \\
\text { capabilities } \\
\text { - GPS Tools } \\
\text { - Mobile GPS \& Apps } \\
\text { - Remote Sensing Software including } \\
\text { Radar Tools } \\
\text { - If sufficient Internet/network }\end{array}$ & $\begin{array}{l}\text { - maps showing } \\
\text { damaged infrastructure } \\
\text { (e.g. roads, electricity, } \\
\text { water supply) } \\
\text { - mapping of the } \\
\text { locations and needs of } \\
\text { affected people } \\
\text { - monitor relief efforts, } \\
\text { such as locations of } \\
\text { rescue teams and } \\
\text { supplies (e.g. food, }\end{array}$ \\
\hline
\end{tabular}




\begin{tabular}{|l|l|l|l|}
\hline $\begin{array}{l}\text { Management } \\
\text { phase }\end{array}$ & $\begin{array}{l}\text { Geoinformatic } \\
\text { activity }\end{array}$ & $\begin{array}{l}\text { Corresponding FOSS4 geoinfo desktop } \\
\text { software }\end{array}$ & $\begin{array}{l}\text { Potential products of } \\
\text { geoinformatic activity }\end{array}$ \\
\hline & $\begin{array}{l}\text { capabilities and expertise exist: } \\
- \text { Geospatial CMS }\end{array}$ & fresh water) \\
\hline $\begin{array}{l}\text { Disaster } \\
\text { recovery }\end{array}$ & $\begin{array}{l}\text { Data dissemination } \\
\text { \& data Sharing }\end{array}$ & $\begin{array}{l}\text { - Desktop GIS } \\
\text { - Mobile GIS \& Apps } \\
\text { If sufficient Internet/ Network } \\
\text { capabilities and expertise exist: } \\
\text { Geoserver, Geospatial CMS, Web- } \\
\text { Applications, Cloud Storage }\end{array}$ & $\begin{array}{l}\text { - monitoring and } \\
\text { sharing of damage } \\
\text { assessments }\end{array}$ \\
\hline & & & $\begin{array}{l}\text { - monitoring of the } \\
\text { distribution of supplies } \\
\text { coordination of } \\
\text { reconstruction } \\
\text { activities }\end{array}$ \\
\hline
\end{tabular}

\subsection{Desktop and mobile GIS software}

The majority of geoinformatic analysis is still performed on workstations with desktop software, despite the increasing opportunities provided by parallel and cloud-computing. With disaster response, typical Desktop GIS software tasks include the display, query, update, and analysis of locational data and their linked information (Steiniger and Bocher, 2009; ESRI, 2012). Software libraries, such as GDAL (for raster data) and OGR (for vector data), are the backbone of many Desktop GIS software. Most recent GIS software has some form of geospatial database and web functionality. Steiniger and Hunter (2013) identified eight "mature Desktop GIS projects" with functionality comparable to proprietary software and an active international user community: (i) GRASS GIS (Neteler et al., 2012); (ii) Quantum GIS (Hugentobler, 2008);

(iii) ILWIS (Hengl et al., 2003); (iv) uDig (Ramsey, 2007); (v)SAGA (Olaya, 2004); (vi) OpenJump (Steiniger and Michaud, 2009); (vii) MapWindow (Ames et al., 2007); (viii) gvSig (Anguix and Diaz, 2008).

Each of the software projects in Figure. 2 can visualize raster and vector data, perform basic geoinformatic operations and most offer plug-in software to extend functionality; they differ in their processing capabilities and support. The GIS user community has shifted its preferred choice of software, fromILWIS and MapWindow, to QGIS, which is now considered to be more user-friendly and versatile than most other FOSS4geoinfo software (e.g., Chen et al., 2010). 


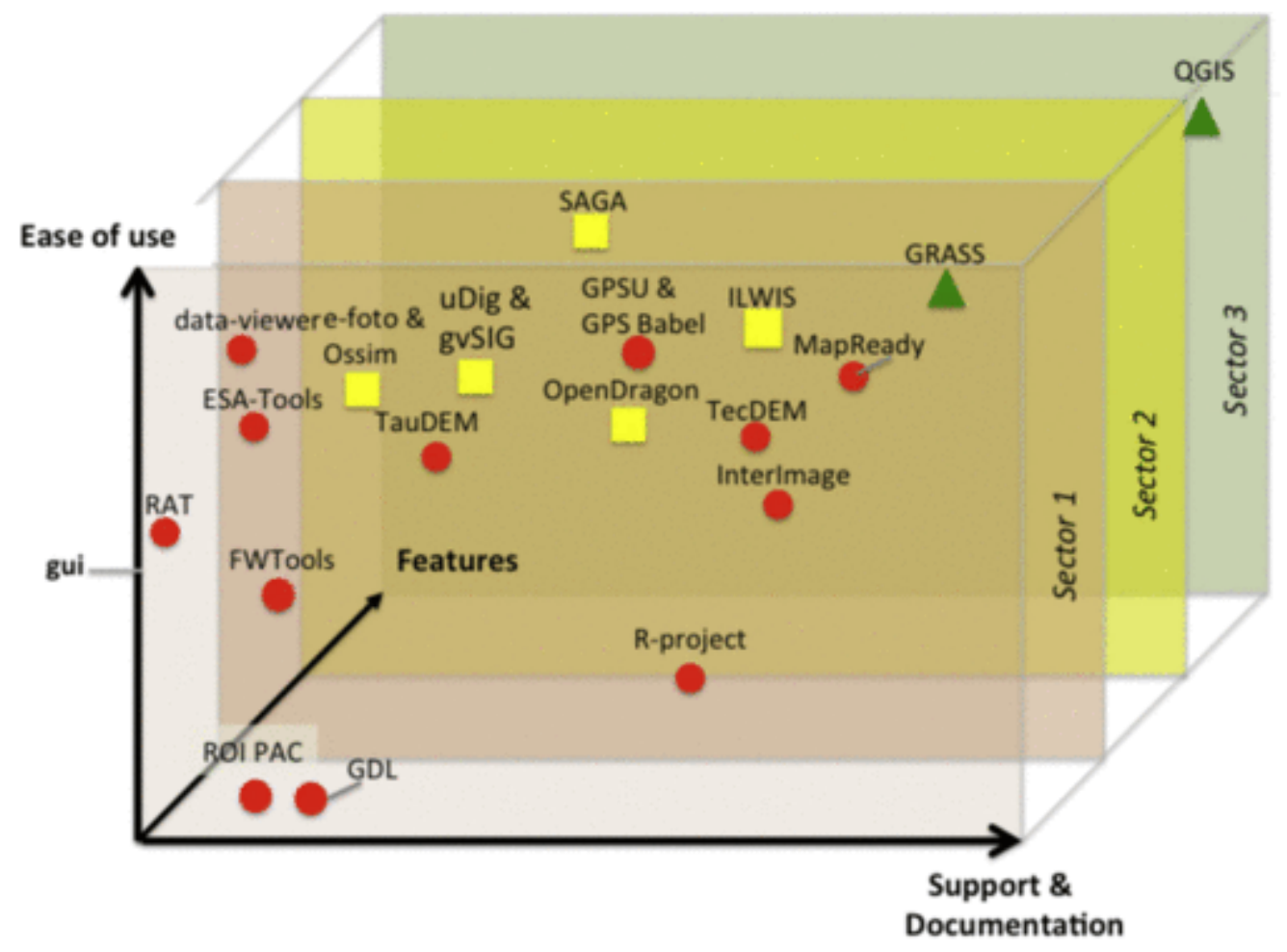

\begin{tabular}{|c|c|c|}
\hline $\begin{array}{l}\text { Feature } \\
\text { sector }\end{array}$ & Description & $\begin{array}{c}\text { Desktop software } \\
\text { (corresponding to Figure 1) }\end{array}$ \\
\hline sector 1 & $\begin{array}{l}\text { Sector } 1 \text { contains software with a limited range of } \\
\text { functions. It is specialized software, covering a } \\
\text { niche or the work with very specific data (such as } \\
\text { Radar remote sensing data). Not all of the } \\
\text { mentioned programmes have a graphical user } \\
\text { interface (gui), such as R. }\end{array}$ & 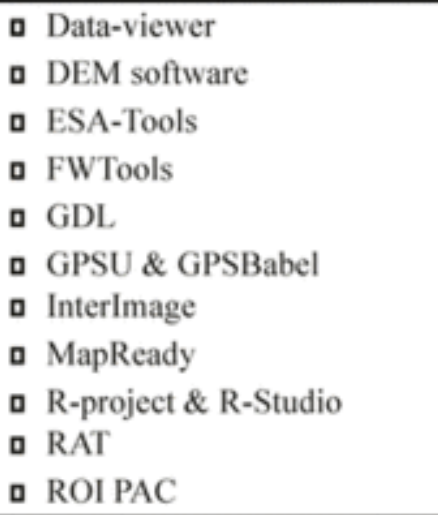 \\
\hline sector 2 & $\begin{array}{l}\text { Software with a wide range of functionality and } \\
\text { modules but lacking advanced processing } \\
\text { capabilities or functionalities (such as ortho- } \\
\text { rectification, or atmospheric correction) or } \\
\text { software that is very strong in one domain, such } \\
\text { as SAGA for raster data analysis and processing, } \\
\text { but lacking vector data handling capabilities. }\end{array}$ & 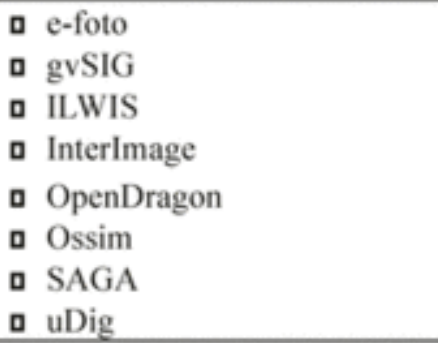 \\
\hline sector 3 & $\begin{array}{l}\text { Software in this sector generally has the most } \\
\text { modules and functionality on its own or by } \\
\text { linking with other FOSS4geoinfo projects. }\end{array}$ & $\begin{array}{l}\text { - QGIS } \\
\text { a GRASS }\end{array}$ \\
\hline
\end{tabular}

Fig. 2 Relationship of features, ease of use and support of the FOSS4 geoinfo in the DM context of Fig. 2.

Although the number of mobile phones has increased, along with the corresponding network-coverage and network-speed, few disaster management applications run on mobile platforms, such as mobile phones or tablets. There are many navigation software apps for mobile devices, but most cannot export data. Two 
exceptions, which allow the export of GPS data, are TangoGPS (http://www.tangogps.org/) and FoxtrotGPS (http://www.foxtrotgps.org/). Data collected by mobile devices might also require processing on workstations with Desktop GIS. Usability of mobile platforms is further limited by the often small display screens, limiting operational activity.

Amongst the geoinformatic software available for mobile devices the Android platform dominates, with the availability of gVSIG Mobile and QGIS. Notable mobile phone apps with disaster management uses are: Geopaparazzi, an Android app for engineering geology surveys: it can store georeferenced notes and images, log GPS tracks, create a map for navigation and export data; GeoNotes, an iOS app that works as a notebook tool, automatically associating a data log with its GPS location and showing user-selected "hot spots"; EpiCollect and its derivative, Magpi: Android apps for epidemiological surveys. Some commercial app-builders provide free basic functionality, but there is also an effective free alternative, with the MIT app inventor. The mobile device apps scene changes rapidly and to assist project continuity a critical mass of users and developers is needed.

\subsection{Web applications, content management systems and cloud storage}

There are a number of web-applications that could support aspects of disaster management, notably:

\subsubsection{Goolge services and software}

Drive (cloud storage and sharing), Fusion Tables (spreadsheet and visualization), Docs (online light version for documents), Sheets (online light version for spreadsheets), Notes (online Notepad); Google Earth Pro, freely available since February 2015: allows adding and displaying of geospatial data-formats, such as shp and geotiff on a virtual globe.

\subsubsection{Microsoft services}

OneDrive (cloud storage and sharing), Excel-Online (online version of Excel), Word-Online (online version of Word), Microsoft OneNote (taking and sharing digital notes).

\subsubsection{EtherCalc}

Open Source spreadsheet software that could be installed for collaborative work. Online services require fast Internet connections; however, in developing countries the Internet is often limited by poor access and slow speeds. Reliability of service is an issue; for instance, as of January 2015, the Google Fusion Table application only has a 'Beta' status: it could be deleted or changed by Google at any time. The advantage of using the commercial services is that they are reliable, with their server-farms distributed globally to archive an online time of $99.99 \%$, improving their resilience in disaster situations. 
Content management systems (CMS) and Wikis are computer applications, often presented online as in form of websites that allow users to publish, edit and organize content from a central interface. Content management systems are often used to provide information and procedures to manage workflows in collaborative environments. A Geospatial CMS provides some of the following features: geospatial data storage; integrated online data editing; data publishing with integrated maps; configuration of map layouts and symbols; data publishing through OGC standards-compliant web services, such as WMS and WFS; map output through GeoWebCache; privilege handling and data security; content publication workflow and revision moderation; metadata collection via a GeoServer-GUI. Wordpress and Drupal are general-purpose CMS, but they have a few geospatial capabilities via their plugin options. Cartarois a web mapping platform that uses PostGIS, GeoServer, GeoWebCache and OpenLayers, all managed from within Drupal: hence Cartaro can be considered as a 'true' geospatial CMS. A CMS is most useful in the preparedness phase of disaster management; however, it can also be used during the disaster response phase, to share information among the various parties, either online or in local networks. To be effective during disaster response would require all contributing parties to be familiar with the system. Hence, for the disaster response phase, a Geospatial CMS may not have priority, although it could enhance the work-flow among trained parties, by direct access to each other"s knowledge stores and avoiding communication bottlenecks by using liaison personnel. Further discussion on the advantages and disadvantages of CMS for disaster management applications, is provided by Yates and Paquette (2011), with a case study from the 2010 Haiti Earthquake.

Cloud storage and online sharing has become increasingly important with the frequently multi-national dimension of disasters. There is often uncertainty regarding privacy and data security with commercial cloud-storage providers. One solution is to store and share data on one"s own servers, although that requires expertise to operate and it might be disrupted during emergencies. Noteworthy FOSS, in terms of stability, user community and commercial support, are: OwnCloud and Pydio.

\subsection{Remote sensing and additional geoinformatic software}

The main tasks of remote sensing software are: image correction, geo-referencing and ortho-rectification, mosaicing of adjacent image scenes, vectorization and image object extraction. Desktop GIS software often offers functionality for remotely sensed data, while remote sensing software has also gained more mapmaking capabilities: thus the boundary between GIS and remote sensing software has diminished. Notable FOSS4geoinfo remote sensing software are: OSSIM: provides image geo-referencing and mosaicing, but the gui is not user-friendly; OpenDragon: "high-quality, commercial-grade, free remote sensing image processing software to schools and universities" (OpenDragon, 2014); e-foto: an educational photogrammetric softcopy kit (Mota et al., 2012); InterImage: provides Object-Based Image Analysis (OBIA), which is dominated by the effective but expensive eCognition software (Camargo et al., 2012). 
QGIS, ILWIS and GRASS GIS software also provide image-processing functions, such as geo-referencing (Table 2). There are also some useful niche products, especially for the work with Digital Elevation Models (DEMs). With the recent availability of free satellite radar data (ESA, 2014), the demand for radar image processing freeware is likely to increase. Notable user-friendly freeware for radar data processing are MapReady, RAT (RAT, 2014) and a number of ESA tools e.g., for Sentinel-1 or the PolSAR pro software.

Table 2 Guidelines on selecting desktop PC software for disaster management uses.

- Check the software functionality: the software must be appropriate for the given task.

- Avoid switching between different sets of software, to reduce the risk of errors and incompatibilities.

- Software stability and platform support must be robust, especially when working in heterogeneous operating system working environments.

- A graphical user interface (gui) is important when aiming to use software with non-experts; it also makes the creation of training material easier, as the required steps can be illustrated by screenshots, rather than command lines, which are often poorly recognized or mis-copied.

- An active user community is needed (preferably international) to ensure development and support, e.g., via online forums.

\subsection{Social media and volunteered geographical information (VGI)}

Every human is a 'sensor' and could be used to provide data and information about their geographical surroundings (Goodchild, 2007). Social media consist of tools that allow the exchange of information through conversation and interaction (Yin et al., 2012). Facebook has over 1.3 billion users and Twitter has over 645 million (Statisticbrain, 2014a,b); Google Earth is accessed more than 1 billion times per month (Searchengineland, 2014); Flickr, with its capability to display georeferenced photos, has over 60 million publicly-accessible photo uploads per month (Flickr, 2014). Houston et al. (2015) review social media for emergency planning and crisis response; while examples of social media performance for disaster management can be found in Bird et al. (2012),Butler (2013), Goodchild and Glennon (2010), Kaufhold and Reuter (2014) and Zisgen et al. (2014).

The collaborative mapping performed by OpenStreetMap (OSM) after the 2010 Haiti earthquake is an example of Volunteered Geographic Information (VGI). OSM rapidly provided accurate maps: the road network map of Port-au-Prince, was almost blank before the disaster, but was nearly complete 10 days later (Roche et al., 2013). Projects such as Ushaidi (http://www.ushahidi.com/) 
and Tomnod (http://www.tomnod.com) provide examples of how volunteers could assist with crisis response mapping. Ushahidi enables people to report the situation they are in and provides situational information for the emergency services. Implicit here is access to the Internet or mobile networks, which may not be the norm in a crisis situation or in remote areas. Ushahidi is open source and freely available, but its setup and documentation leave room for improvement. Tomnod is entirely controlled by Digital Globe Inc.,: it is not obvious how mapping done by Tomnod volunteers is distributed. Furthermore, with Ushaidi and Tomnod there is no indication of quality control measures.

The reliability of data obtained by VGI should be judged on a case-by-case basis (Glushko, 2014). VGI is best used in combination with official data e.g.,for updating maps in an emergency situation in near real-time, such as wildfires (Goodchild and Glennon, 2010). There is a need to incorporate VGI capabilities into future GIS desktop software, beyond virtual globes such as GoogleEarth. An important consideration for VGI software is the ability to detect and ignore doubtful contributions (Goodchild, 2007; Flanagin and Metzger, 2008). Recent research, such as automated geographic context analysis, has made VGI more reliable (Spinsanti and Ostermann 2013). A promising approach was by Bishr and Kuhn (2007), who proposed that trust should be used as a proxy for VGI quality, demonstrated in the form of user ratings.

\section{Criteria to select software for disaster management applications}

Various authors have proposed evolution criteria for free GIS (e.g. Cruz et al., 2006; Wagner, 2006; Steiniger and Bocher, 2009). Many FOSS4geoinfo software products can compete with proprietary software. Furthermore, in general, "open source software not only has better than average quality as compared to the industry average, but in fact continues to raise the bar on what is considered good quality software for the entire industry" (Coverity, 2013). Advice on selecting desktop PC software for disaster management is summarised in Table 2, based on observations from geoinformatic training sessions carried out by the authors in European, Caribbean, African and Asian environments. For FOSS4geoinfo novices, the Field guide for Humanitarian Mapping (MapAction, 2012) provides guidance based on extensive experience in the disaster response sector.

Many FOSS4geoinfo projects ship as a software bundle, such as the gvSIG Community Edition project, which bundles gvSIG, GRASS and SAGA. QGISships with GRASS and SAGA, which allow raster-processing capabilities, without leaving the user-friendly QGIS interface for the more complex gui of SAGA. A combination of the QGIS bundle and GPS Utility or GPS Babel can deal with almost any spatial analysis or mapping task required in disaster management. There is extensive QGIS support through its user community (e.g., via online forums) and a large number of plugins are available. Some GIS freeware have an advantage over the leading proprietary GIS (ArcGIS), in that they support more coordinate systems. ArcGIS can be extended by downloading required projections and coordinate transformations (e.g., via http://spatialreference.org/ or http://www.epsg.org/), but that might be difficult for GIS novices. 
Many FOSS4geoinfo projects have a further advantage: they support multiple operating systems, usually at least Microsoft Windows and Linux, while proprietary software is often limited to Windows environments. With Linux it is often faster to apply corrections provided by user-forums, than waiting for a new compiled version to be produced for Windows. In general, Linux should be considered as a primary operating system: it is freely available and tends to perform better on older hardware (which often predominates in LICs).

\section{Recent FOSS4geoinfo developments}

Many FOSS4geoinfo projects, especially in the GIS domain, have developed rapidly in recent years and attracted many users and developers. One example is the 'System for Automatic Geoscientific Analysis' (SAGA: Böhner et al., 2006), which is frequently updated and available for Windows and Linux. An advantage of SAGA is its university-driven development, with access open for other developers to make enhancements. That is an improvement on FOSS4geoinfo projects where the software is no longer updated, or is discontinued, when the main developer leaves (e.g., RAT). Software development is closely linked to developments of analytical techniques, statistical theory and methods, as well as technological advances, such as computer hardware improvements (Cheng et al., 2012). It is likely that university research groups will provide more development in the FOSS4geoinfo domain in future, as indicated by ICAOSGeo Labs and the Geoforall imitative, with over 80 Labs established since 2011 (Geoforall, 2014). However, the development of larger FOSS4geoinfo projects in future seems unlikely: some universities or individuals may cover niche applications, but getting the required resources (finances, developers and crucial mass of users) has become more challenging.

Data availability is an important factor for the progress of FOSS4geoinfo. On the arrival of a new type of freely available data, there will be a demand for new software to process it, e.g., with the recent supply of data from ESA"s Sentinel satellites. Making adequate use of new types of geospatial data requires an update of existing software but also provides an opportunity for new software development. Highresolution commercial satellite imagery, with a spatial resolution of less than $50 \mathrm{~cm}$, will soon be available (Teeuw et al., 2012), resulting in bigger volumes of data and new processing requirements for the associated software.

In disaster response, most GIS work is done on desktop workstations or laptops; maps remain the main medium for displaying spatial information, especially in the disaster aftermath, where fast data-sharing and information presentation are essential. However, high-performance computing (HPC), cloud-computing and parallel computing are likely to be increasingly used, especially for large disaster preparedness projects, such as the INSPIRE tsunami modelling project (Srivihok et al., 2012). The methods currently applied for parallel-computing on HPCs will become more relevant for workstations since multi-core central processing units (CPUs) and powerful graphical processing units (GPUs) become a standard. One issue of implementation, apart from the availability of the required algorithms, is that the license-fee of some 
proprietary software is linked to the available CPU cores. Hence, multi-core CPU and GPU processing applications are an opportunity for FOSS4geoinfo. It will cut software costs (e.g., currently a number of proprietary software licenses are priced based on the used cores which could be avoided by using freely available software) and make FOSS of even more interest to companies, which might aid FOSS development. Some GPU computing capabilities are included in the R statistical freeware and some proprietary software, notably PCI Geomatica and ERDAS Imagine (McCallum and Weston, 2011). Although GPU cores are slower than CPUs, there are thousands of GPU cores, even on modern laptop graphic boards. Using thousands of GPUs theoretically allows processing possibilities, which have previously been limited to HPCs. Hence software development has to make better use of the currently available hardware.

With the globally increasing number of smartphones and mobile devices, there is the potential for more disaster management apps. The development of a new app usually requires relatively few resources; also, as there is less competition, a new app is more likely to make an immediate impact. 3D visualization is still limited, not only in the FOSS4geoinfo sector, but also with proprietary software, although this is likely to improve with the cheaper supply of high-resolution data (Cheng et al., 2012). Examples are the growing use of LiDAR laser scanning and digital photography from Unmanned Aerial Vehicles (drones).

Free GIS software, such QGIS and linked tools, have become widely used in disaster response. QGIS has been used as an alternative for ESRI's ArcGIS in many recent deployments by MapAction (http://www.mapaction.org/deployments.html). In addition MapAction is increasingly using QGIS for introducing GIS and mapping to the information managers of other disaster response organisations. Recent examples where QGIS has been used in disaster management or for humanitarian response are given below (pers. comm. MapAction, 2015):

- Iraq 2014: QGIS used by MapAction in support of the World Food Program, for Food Cluster management;

- Panama 2014: QGIS used by the support mission for Situations of Violence in the Northern Triangle of Central America (ACAPS, 2014);

- Nepal 2015: earthquake response; information managers dealing with education and shelter used QGIS, with initial guidance from MapAction.

Furthermore, volunteers of Médecins Sans Frontières and members of the International Federation of Red Cross/Red Crescent Societies (IFRC) have been using QGIS in West Africa for mapping and monitoring the 2014-2015 Ebola crisis (Cozma, 2015 pers. comm., May 2015).

\section{Challenges for FOSS4geoinfo with disaster management tasks}

A key challenge is to select the best software for a given geospatial problem. For most disaster management tasks there is sufficient FOSS4geoinfo software. Within the GIS domain, freely available 
software that can perform all required tasks. That is not the case in the remote sensing domain, but with the increasing availability of free data that might change, and freely-available remote sensing functionality will become closer to its commercial counterparts. The challenge for freeware remote sensing projects is to find the required crucial user-mass to ensure widespread usage and development. A good resource for testing FOSS4geoinfo functionality is provided by the OSGeo LiveDVD, which is a bootable DVD containing prominent FOSS4geoinfo software, including various Desktop GIS, Webservers and command line tools (OSGeo-Live, 2014).

It is essential that the development of freely-available software is linked to freely-available training materials, to attract and train as many users as possible. A downside of many current FOSS projects is limited documentation and user support. FOSS4geoinfo support tends to be limited to online forums or email lists that require free access to the Internet, which can be problematic in LICs. Hopefully the usersupport issue will improve with more universities or institutions getting involved in training and projects such as the Open-Source Geo Labs. OsGeo.org and GeoForAll are two umbrella initiatives for FOSS4geoinfo, but they do not cover all projects and research. Many initiatives focused on disaster management, such as the 3-Free-Guide (free data, free software, free training: Leidig and Teeuw, 2014), or websites providing help for geospatial problems (e.g.,http://freegeographytools.com/ or http://gis.stackexchange.com/), could be linked with Geoforall, OsGeo.org or the UN-Spider Free Data Sources website (UN-Spider, 2014).

Better use of existing hardware is desirable, especially multi-core CPU and GPU processing support. This includes agreement on standards, from data formats to appropriate disaster management methodologies. For instance, geotiff is currently the most widely used and supported raster data format; however, its $4 \mathrm{~Gb}$ file size limit is a handicap, e.g., if mosaicing high-resolution satellite images. With increasing amounts of geospatial data, there is a need for advanced data compression methods, such as a free license for ecw or mrsid. Sustainable use of FOSS4geoinfo would benefit from a change of operating system, from Microsoft Windows to Linux, which runs more easily on the older PCs found in many LICs than the latest versions of Microsoft Windows.

Projects such as Ushahidi and Tomnod provide examples of how a large group of volunteers could be used for situation mapping. The main challenge for similar community-driven projects is: how to get adequate (and accurate) data? Many of the risks associated with VGI as a data source could be reduced with methods to rank or classify information and by implementing internal accuracy assessments. In principle: the greater the data availability, the more complete the picture of a situation. In addition to the possibility of near realtime information, VGI information obtained from many observers is likely to be closer to 'the truth' than information obtained from one observer. During emergencies, risks associated with volunteered information are outweighed by its benefits: "Costs of acting in response to false positives are generally less than the costs of not acting in response to false negatives" (Goodchild and Glennon, 2010). 


\section{Conclusion}

The installation of only a few items of freely available software will allow users to perform most geoinformatic tasks required for disaster management applications, from preparedness mapping (e.g., maps showing elements at risk, such as critical infrastructure, or safe ground for emergency camps), through to the rapid assessments and frequent situation reports of crisis response. Desktop software capabilities could be enhanced by the incorporation of web applications, given sufficient Internet capabilities and expertise. Provided there is suitable training, even non-experts in geoinformatic data processing can achieve adequate results.

A lot of freeware has poor documentation, limiting its use and possible future development. Personal communication with a number of NGOs has highlighted that many are put off using FOSS4geoinfo because there is often no support-link to the software developers. Small changes, such as software support contacts via email, could significantly increase the application and uptake of FOSS4geoinfo in disaster management.

We hope that this article encourages you to use, or participate in, FOSS4geoinfo projects. The major benefit for users, from individuals to universities and businesses, is the lack of a license fee. Training costs can be greatly reduced by the provision of Internet-deliverable training courses, many of which are freely available. For disaster management applications, FOSS4geoinfo options should be considered and tested against proprietary GIS software. Free geoinformatics can help to optimize the limited financial, technological and manpower resources that many organisations face, providing a sustainable input to disaster management.

\section{References}

ACAPS website: http://acaps.org/en/news/other-situations-of-violence-in-the-northern-triangle-of-centralamerica/1, (accessed 17.06.14.).

Ames D.P., Michaelis C., Dunsford T., (2007). Introducing the MapWindow GIS project. OSGeo Journal, 2. osgeo.org/journal.

Anguix A. and Diaz L., GvSIG: a GIS desktop solution for an open SDI, J. Geogr. Reg. Plann. 1 (3), 2008, 4148.

Bird D., Ling M. and Haynes K., Flooding facebook-the use of social media during the Queensland and Victorian floods, Aust. J. Emerg. Manage. 27 (1), 2012,27.

Bishr M. and Kuhn W., Geospatial information bottom-up: a matter of trust and semantics, The European Information Society, 2007, Springer, (pp. 365-387).

Butler D., Crowd-sourcing goes Mainstream in typhoon response, Nat. News 2013, (accessed 8.9.14.). 
Böhner J., McCloy K.R. and Strobl J., (Eds.), SAGA - Analysis and Modelling

Applications 115, 2006, Göttinger Geographische Abhandlungen, 130.

Camargo F.F., Almeida C.M., Costa G.A.O.P., Feitosa R.Q., Oliveira D.A.B., Heipke C. and Ferreira R.S., An open source object-based framework to extract landform classes, Expert Syst. Appl. 39 (1), 2012, 541554, http://dx.doi.org/10.1016/j.eswa.2011.07.044.

Chen D., Shams S., Carmona-Moreno C. and Leone A., Assessment of open source GIS software for water resources management in developing countries, J. Hydro-Environ. Res. 4 (3), 2010, 253-264.

Cheng T., Haworth J. and Manley E., Advances in geocomputation (1996-2011), Comput. Environ. Urban Syst. 36 (6), 2012, 481-487.

Coverity, (2013). Coverity Scan: 2013 Open Source Report.

Cozma, V. (May, 2015) Pers. Comm. with Teeuw: Cozma has been using QGIS for mapping \& monitoring of Ebola cases since May 2014, with the Sierra Leone Red Cross Society and then with the IFRC.

Cruz D., Wieland T. and Ziegler A., Evaluation criteria for free/open source software products based on project analysis, Software Process Improv.d Pract. 11, 2006, 107-122.

Das S., The role of natural ecosystems and socio-economic factors in the vulnerability of coastal villages to cyclone and storm surge, Nat. Hazards 64 (1),2012, 531-546.

ESA - Free Sentinel Satelite data

website:http://www.esa.int/Our_Activities/Observing_the_Earth/Copernicus/Free_access_to_Copernicus_ Sentinel_satellite_data, (accessed 09.07.14).

ESRI - Environmental Systems Research Institute (2012). GIS Dictionary: desktop-

GIS.http://support.esri.com/en/knowledgebase/Gisdictionary/term/desktop-GIS>, (accessed 17.06.14.).

Flanagin A.J. and Metzger M.J., The credibility of volunteered geographic information, GeoJournal 72 (34), 2008, 137-148.

Free Software Foundation, 2014. website: http://www.fsf.org/, (accessed 17.06.14.).

Geoforall, 2014. website: http://www.geoforall.org, last (accessed 17.06.14.).

Glushko S., (2014). Volunteered Geographic Information. Retrieved 29.06., 2014.

GNU, 2014. org website: https://gnu.org/philosophy/free-sw.html, accessed 17.06.2014.

Goodchild M.F., Citizens as voluntary sensors: spatial data infrastructure in the world of web 2. 0, Int. J. 2, 2007, 24-32. 
Goodchild M.F. and Glennon J.A., Crowdsourcing geographic information for disaster response: a research frontier, Int. J. Digital Earth 3 (3), 2010, 231-241.

Grassmuck, V., (2004). Freie Software zwischen Privat- und Gemeineigentum (vol. 458). Bonn: Bundeszentrale für politische Bildung. http://freie-software.bpb.de/.

Hengl, T., Gruber, S., Shrestha, P.D., (2003). Digital terrain analysis in ILWIS, http://www.itc.nl/library/papers_2003/misca/hengl_digital.pdf, (accessed 17.01.12.).

Houston, J. B., Hawthorne, J., Perreault, M. F., Park, E. H., Goldstein Hode, M., Halliwell, M. R., Turner McGowen, S. E., Davis, R., Vaid, S., McElderry, J. A. and Griffith, S. A. (2015), Social media and disasters: a functional framework for social media use in disaster planning, response, and research. Disasters, 39: 1-22. Hugentobler, M., (2008). Quantum GIS. In: S. Shekhar \& H. Xiong (eds.), Encyclopedia of GIS (pp. 935 - 939 ). New York: Springer. iTunes GeoNote website: https://itunes.apple.com/de/app/geonotes-rememberlocation/id595084320?mt=8, accessed 17.6.2014.

Kaufhold, M.-A., Reuter, C., (2014). Vernetzte Selbsthilfe in Sozialen Medien am Beispiel des Hochwassers 2013. i-com, 1, 20.

Leidig, M., Teeuw, R.M., (2014). Quick Guide to Free Geoinformatics for Disaster Management: http://research.mlabs.org.uk/blog/?page_id=20, (accessed 17.6.14.).

MapAction, (2012). Field guide to Humanitarian Mapping, available at http://www.mapaction.org/.

MapAction, (May 2015) Pers. Comm. with Leidig: details of recent deployments where QGIS was used were provided by members of the MapAction information management team.

McCallum, Q. E., Weston, S. (2011). Parallel R. Sebastopol, CA: O'Reilly Media.

Mota G.L.A., Nunes e Silva Brito J.L., Araujo Ribeiro J., Bernardo Filho O., Teixeira Silveira M. and Alves de Aguiar R., The efoto project and the research to implement a GNU/GPL open source educational digital photogrammic workstation?, In: Bocher E. and Netler M., (Eds.), Geospatial free and open source software in the 21st century, 2012, Springer; Heidelberg, 89-106.

Neteler, M., Bowman, M. H., Landa, M., Metz, M., (2012). GRASS GIS: A multi-purpose open source GIS. Environmental Modelling \& Software, 31(May), 124-130.

Olaya, V., (2004). A gentle introduction to SAGA GIS. http://downloads.sourceforge.net/sagagis/SagaManual.pdf, (accessed 17.6.14.).

OpenDragon, 2014. website: http://www.open-dragon.org/, (accessed 17.6.14.). 
OSGeo-Live, 2014. http://live.osgeo.org, (accessed 17.6.14.).

Ramsey, P., (2007). The state of open source GIS. In Presentation at FOSS4G 2007, Vancouver, Canada: http://refractions.net/expertise/white-papers/, (accessed:17.6.14.).

RAT, 2014.pdf: https://www.cv.tu-berlin.de/fileadmin/fg140/RAT_Radar_Tools_.pdf, (accessed 15.6.14.).

Roche S., Propeck-Zimmermann E. and Mericskay B., GeoWeb and crisis management: issues and perspectives of volunteered geographic information,GeoJournal 78 (1), 2013, 21-40.

Spinsanti L. and Ostermann F., Automated geographic context analysis for volunteered information, Appl. Geogr. 43 (0), 2013, 36-44.

Srivihok P., Honda K., Ruangrassamee A., Muangsin V., Naparat P., Foytong P. and Layug J.E., Development of an online tool for tsunami inundation simulation and tsunami loss estimation, Cont. Shelf Res. 79, 2012, 3-15.

Stallman, R.M., (1999). The GNU operating system and the free software movement. In: C. DiBona, S. Ockman \& M. Stone (eds.), Open sources: Voices from the open source revolution (pp. 53-50). Sebastopol: O'Reilly.

Statisticbrain, 2014. website: http://www.statisticbrain.com/facebook-statistics/, (accessed 09.07.14.).

Statisticbrain, 2014. website: http://www.statisticbrain.com/twitter-statistics/, (accessed 09.07.2014.).

Searchengineland, 2014. website: http://searchengineland.com/, (accessed 09.07.14.).

Steiniger S. and Bocher E., An overview on current free and open source. desktop GIS developments, Int. J. Geogr. Inf. Sci. 23 (10), 2009, 1345-1370.

Steiniger, S., Michaud, M. (2009). The Desktop GIS OpenJUMP: A hands-on introduction. In: OGRS 2009 workshop, Nantes, France.http://sourceforge.net/projects/jump-pilot/files/Documentation/, (accessed 17.06.14.).

Steiniger S. and Hunter A.J.S., The 2012 free and open source GIS software map - A guide to facilitate research, development and adoption, Comput. Environ. Urban Syst. 39 (0), 2013, 136-150.

Teeuw R.M., Leidig M., Saunders C. and Morris N., Free or low-cost geoinformatics for disaster management: uses and availability issues, Environ. Hazards 2012, 1-20.

UN-Spider, 2014. Free Data Sources website: http://www.un-spider.org/data\#Satellite_Data, (accessed 17.06.14.).

UNESCO, 2014. website: http://www.unesco.org, (accessed 17.06.14.). 
Wagner, J.O. (2006). Quo Vadis Desktop-GIS? Procs. Quo Vadis GIS workshop, WhereGroup 21, Bonn, Germany.http://www.wheregroup.com/files/DesktopGIS.pdf, (accessed 17.06.14.).

Yates D. and Paquette S., Emergency knowledge management and social media technologies: a case study of the aitian earthquake, Int. J. Inf. Manage. 31 (1),2011, 6-13.

Yin J., Lampert A., Cameron M., Robinson B. and Power R., Using social media to enhance emergency situation awareness, IEEE Intell. Syst. 27 (6), 2012,52-59.

Zisgen J., Kern J., Thom D. and Ertl T., Using visual analytics of social media in civil protection, icom 13 (1), 2014, 37-44 